\title{
O ESTADO DE COISAS INCONSTITUCIONAL EM MATERIA AMBIENTAL: SEUS FUNDAMENTOS NA ADO 60/DF
}

\author{
Airton Roberto Guelfi \\ Universidade do Oeste Paulista - UNOESTE, Presidente Prudente, SP. E-mail: del.guelfi@gmail.com
}

\section{RESUMO}

Este artigo teve por objetivo evidenciar os fatores fundamentais que subsidiaram a recente decisão de estado de coisas inconstitucional em matéria ambiental no Brasil, proferida pelo Ministro Luís Roberto Barroso junto a ADO 60/DF. A pesquisa foi do tipo bibliográfica e documental e sua abordagem foi de natureza qualitativa. Os resultados restaram evidenciados na seara social através das diversas manifestações de hostilidades do Governo Federal contra pessoas físicas e jurídicas engajadas na defesa do meio ambiente, na seara política através da decisão de extinção e remanejamento de diversos órgãos ligados a defesa dos recursos naturais e na seara administrativa através do desligamento de diversos agentes públicos ocupantes de cargos destacados na temática sobre a proteção do meio ambiente. Em conclusão, restou evidenciado que o Brasil se encontra num verdadeiro estado de coisas inconstitucional em matéria ambiental, com massivas ações e omissões responsáveis pela exploração insustentável dos recursos ambientais, eclodindo a necessária atuação do Supremo Tribunal Federal como Corte Constitucional responsável pelo apontamento das atuações necessárias e respectiva fiscalização de suas realizações.

Palavras-Chave: Estado de coisas inconstitucional. Meio Ambiente e Direito Fundamental. Fatores do estado de coisas inconstitucional em matéria ambiental.

\section{UNCONSTITUTIONAL STATE OF AFFAIRS IN ENVIRONMENTAL MATTERS: ITS FUNDAMENTALS IN ADO 60 / DF}

\begin{abstract}
This article aimed to highlight the social, political and administrative factors that underpinned the recent unconstitutional state of affairs decision on environmental matters in Brazil, issued by Minister Luís Roberto Barroso at ADO 60/DF. The research was bibliographic and documentary and its approach was of a qualitative nature. The results remained evident in the social field through the various manifestations of hostilities of the Federal Government against individuals and legal entities engaged in the defense of the environment, in the political field through the decision to extinguish and relocate various bodies linked to the defense of natural resources and in the field administrative through the dismissal of several public agents occupying positions highlighted in the theme on the protection of the environment. In conclusion, it remains evident that Brazil is in a real state of affairs unconstitutional in environmental matters, with massive actions and omissions responsible for the unsustainable exploitation of environmental resources, resulting in the necessary performance of the Supreme Court as a Constitutional Court responsible for pointing out the actions and the respective inspection of their achievements.
\end{abstract}

Keywords: unconstitutional state of affairs. Environment and Fundamental Law. Factors of the unconstitutional state of affairs in environmental matters. 


\section{INTRODUÇÃO}

$O$ estado de coisas inconstitucional (ECI) em matéria ambiental é um tema timidamente difundido e explorado pelos acadêmicos brasileiros em razão de sua recenticidade junto ao cenário jurídico nacional, despertando naturalmente recorrentes dúvidas quanto aos reais fatores de sua concepção e quanto as necessárias discussões circundadas em seu quadro ontológico.

A presente pesquisa, então, ao trazer para o centro do debate os fatores responsáveis pela concretização do $\mathrm{ECl}$ em matéria ambiental no Brasil, justifica-se pela relevância social, pela relevância acadêmica e, ainda, pela contribuição inédita e atual que dá aos estudos do Direito no Brasil, nos campos do direito constitucional e direito ambiental, esclarecendo quais medidas são necessárias ao enfrentamento da crise ambiental que se instalou nas mais diversas camadas do governo e da sociedade.

A problemática almejada no artigo corresponde a identificação de quais são os fatores responsáveis pela formação do $\mathrm{ECl}$ em matéria ambiental no território brasileiro.

Tais fatores são responsáveis por diversas falhas de natureza estrutural, junto ao cenário político-administrativo do Estado Brasileiro, violando direitos fundamentais da pessoa humana através da desconsideração do meio ambiente ecologicamente equilibrado.

Quanto ao seu objetivo geral, aspira-se evidenciar tais fatores e suas respectivas naturezas, responsáveis pela formação do atual estado de coisas inconstitucional em matéria ambiental no cenário político brasileiro, a partir de recente decisão proferida pelo Ministro Luís Roberto Barroso junto a ADO 60/DF.

A evidenciação premente dos fatores e suas respectivas naturezas possibilitarão à sociedade compreender o verdadeiro cenário de "estado de coisas" vivenciado pelos ecossistemas no território brasileiro, assim como norteará as ações públicas e privadas destinadas a arrefecer violações massivas ao direito fundamental do meio ambiente ecologicamente equilibrado.

Sobre os objetivos específicos, a investigação buscará explicar, num primeiro instante, as bases de um meio ambiente ecologicamente equilibrado como verdadeiro direito fundamental da pessoa humana. Num segundo momento, buscará esclarecer o significado do "estado de coisas inconstitucional" dentro a ordem constitucional do Estado Brasileiro. No derradeiro ponto de discussão, a investigação científica identificará quais os fatores, em matéria constitucional ambiental, foram considerados para o reconhecimento do estado de coisas inconstitucional em matéria ambiental junto ao cenário jurídico-políticoadministrativo brasileiro.

Para o genuíno domínio dos fatores estruturantes do estado de coisas inconstitucional em matéria ambiental no cenário jurídico-político-administrativo brasileiro é preciso expandir as noções sobre a natureza fundamental do direito ao meio ambiente ecologicamente equilibrado para as presentes e futuras gerações, na esteira dogmática do artigo 225 da Constituição Federal.

Com a mesma medida crucial, faz-se imediata a compreensão do significado jurídico da teoria do "estado de coisas inconstitucional", partindo de sua raiz colombiana e aportando no cenário constitucional brasileiro, possibilitando assim chegar a identificação do quadro em matéria ambiental.

\section{METODOLOGIA}

A pesquisa será do tipo bibliográfica e documental, aplicada sobre fontes primárias. A abordagem da pesquisa será qualitativa, executada sobre a recente decisão do Ministro Luís Roberto Barroso junto a ADO 60/DF e artigos científicos relacionados ao tema do meio ambiente como direito fundamental, estado de coisas inconstitucional e sua aplicação na matéria ambiental no Brasil. Quanto ao método, este será o dedutivo, identificando os fatores que compõem o estado de coisas inconstitucional no cenário jurídico-político-administrativo brasileiro.

\section{RESULTADOS E DISCUSSÃO.}

A discussão referente ao estado de coisas inconstitucional em matéria ambiental no Brasil parte necessariamente do reconhecimento do meio ambiente como um direito fundamental do ser humano, sustentáculo de tantos outros direitos fundamentais como a vida e saúde.

\subsection{O meio ambiente como direito fundamental.}

Foi com o advento da terceira dimensão de direitos fundamentais, caracterizados pela preocupação com a qualidade de vida e a solidariedade humana, que o meio ambiente 
passou a deitar raízes entre os chamados "direitos da fraternidade", como verdadeira essencialidade a preservação do patrimônio comum da humanidade (GOMES, 2007).

Nas últimas décadas, o meio ambiente tornou-se um bem tutelado por constituições, tratados internacionais e legislações infraconstitucionais em todo o planeta. No Brasil não foi diferente, sendo que a expressão máxima desta fundamental proteção foi esculpida no artigo 225, "caput", da Constituição Federal, com a seguinte redação: "Todos têm direito ao meio ambiente ecologicamente equilibrado, bem de uso comum do povo e essencial à sadia qualidade de vida, impondo-se ao Poder Público e à coletividade o dever de defendê-lo e preservá-lo para as presentes e futuras gerações."

Sobre a constitucionalização do meio ambiente ecologicamente equilibrado ocorrida em 1988, Edis Milaré (2000, p. 82) destacou que “(...) com a promulgação da nova Constituição Brasileira, onde o progresso se fez notável, na medida em que a Magna Carta deu ao meio ambiente uma disciplina rica, dedicando à matéria um capítulo próprio em um dos textos mais avançados em todo o mundo".

Professando sobre o fundamento desta constitucionalização ambiental, Solange Teles da Silva (2006, p. 172) afirma que:

$$
\begin{aligned}
& \text { O fundamento da } \\
& \text { constitucionalização do } \\
& \text { direito ao meio ambiente } \\
& \text { é a própria dignidade da } \\
& \text { pessoa humana, das } \\
& \text { gerações presentes e } \\
& \text { futuras. De maneira mais } \\
& \text { abrangente é possível } \\
& \text { afirmar que o fundamento } \\
& \text { da consagração de um } \\
& \text { direito ao meio ambiente } \\
& \text { ecologicamente } \\
& \text { equilibrado é a dignidade } \\
& \text { da vida em todas as suas } \\
& \text { formas. Trata-se de } \\
& \text { assegurar a continuidade } \\
& \text { da vida no planeta, } \\
& \text { fundada na solidariedade } \\
& \text { humana no tempo e no } \\
& \text { espaço. }
\end{aligned}
$$

Conforme leciona Canotilho (apud GOMES, 2007), um direito fundamental será assim definido diante de sua positivação no ordenamento jurídico de um determinado país, tendo a natureza de genuíno direito "natural" e "inalienável” de todo ser humano.
Um direito fundamental, a princípio, é caracterizado como um direito subjetivo, ao passo que é posto a todo e qualquer cidadão como forma de utilizá-lo quando necessário, oportuno e interessante, assegurando uma vida digna (ROTHENBURG, 2014). São exemplos desta fundamentabilidade o direito à vida e o direito à saúde.

Tratam-se de liberdades básicas e essenciais para o desenvolvimento individual de cada ser humano. Partindo de uma visão Kantiana, Michaels e Martin (2016, p. 48) descrevem que:

A liberdade constitui, segundo Immanuel Kant, o ponto de partida de uma sociedade esclarecida. A protecção da liberdade pessoal pelo direito tem uma importância de primeira ordem. A garantia de liberdade é um dos pressupostos de legitimidade de toda a ordem jurídica. Os direitos fundamentais figuram, por isso, entre os elementos nucleares de uma Constituição.

A atual Constituição Federal Brasileira revelou um verdadeiro modelo de Estado Socioambiental, conjugando à dignidade da pessoa aos valores ecológicos. Professando sobre o tema, Sarlet, Machado e Fensterseifer (2015, p.36) escrevem que o Estado Ambiental “(...) tem por tarefa proteger e promover os direitos fundamentais, entre eles o direito ao ambiente, cumprindo um papel proativo, comprometido com a implantação de novas políticas públicas para dar conta das novas tarefas na seara ambiental que the foram atribuídas constitucionalmente (art. 225 da CF/88)".

Sob a perspectiva referendada, o constituinte preocupou-se em preservar todo o ecossistema ambiental existente sobre o território brasileiro, assim como atentou-se para a necessidade de restauração daqueles sistemas ambientais já degradados, mas que são essenciais à sadia qualidade de vida (BORGES; ZIESEMER, 2018).

Neste diapasão constitucional, o meio ambiente - em seus aspectos natural, cultural $e$ artificial - corresponde a um direito fundamental amparado pela dignidade da pessoa humana e 
voltado a garantia de outros direitos fundamentais como a vida, a saúde, a segurança alimentar e o acesso a água das presentes e futuras gerações (BRASIL, 2020).

Mas o meio ambiente não deve ser apenas encarado como um bem fundamental em si mesmo. Sua real extensão constitucional o coloca como um verdadeiro sustentáculo de outros tantos direitos fundamentais necessários ao ser humano, um verdadeiro alicerce apto a manter muitos outros direitos fundamentais ao ser humano (MORAIS, 2013).

Assim, é forçoso reconhecer que o Poder Público - visto na vertente de seus poderes Legislativo, Executivo e Judiciário - tem obrigação de atuar para garantir a utilização e preservação do meio ambiente para as presentes e futuras gerações. Não é outro o ensinamento aplicado à sociedade. A coletividade, formada por pessoas físicas e jurídicas de direito privado, também cabe a responsabilidade de usufruir e preservar o meio ambiente, assegurando os interesses atuais e por vir.

Para além de garantias individuais de cunho ambiental, fundamentadas na dignidade da pessoa humana e asseguradas pelo texto constitucional, a proteção do meio ambiente também ganha destaque como interesses difusos, seguindo pela esteira do desenvolvimento de potencialidades sociais, expandida à partir da vida em sociedade de maneira ecologicamente sustentável.

Já em 1972, restou perpetuada a importância do meio ambiente como um direito difuso e essencial a vida humana, junto a Declaração de Estocolmo sobre o ambiente humano, através de seu princípio 01 que diz:

O homem tem o direito
fundamental à liberdade, à
igualdade e ao desfrute de
condições de vida
adequadas em um meio
ambiente de qualidade tal
que lhe permita levar uma
vida digna e gozar de bem-
estar, tendo a solene
obrigação de proteger e
melhorar o meio ambiente
para as gerações
presentes e futuras. (ONU,
1972, p. 01).

Neste passo, a garantia constitucional ao meio ambiente ecologicamente equilibrado apresenta-se sob duas faces intimamente interligadas: a individual e a coletiva. Em ambos os casos, o objetivo é assegurar que indivíduos e coletividades, das presentes e futuras gerações, tenham acesso a uma sadia qualidade de vida através do meio ambiente ecologicamente equilibrado (SILVA, 2006).

Por força desta constitucionalização do meio ambiente, impõe-se como dever ao Poder Público e à toda a coletividade - aqui se inclui toda a iniciativa privada - a preservação dos recursos ambientais, desconsiderando qualquer margem de opção política voltada a exploração insustentável dos recursos ambientais (BRASIL, 2020).

Faz-se presente uma verdadeira necessidade de evolução das tradicionais concepções de soberania governamental, de direito de propriedade e posse e de prevalência dos interesses públicos e individuais, frente a necessária preservação dos recursos ambientais e premente recuperação de cenários já degradados, conciliando parâmetros de Direito Constitucional e Direito Internacional.

A seguir, será apresentada a concepção de "estado de coisas inconstitucional", enquanto teoria constitucional voltada a evidenciar uma condição sistemática de violações de direitos fundamentais.

\subsection{0 "estado de coisas inconstitucional - (eci)".}

A teoria do estado de coisas inconstitucional (ECI) surgiu na Colômbia envolta num processo de judicialização da política e do crescimento do ativismo judicial, precisamente em julgamento da Corte Constitucional Colombiana, a partir da decisão SU-559, de 06 de novembro de 1997, influenciada nos structural remedies dos Estados Unidos (CAMPOS, 2015) e impulsionada pela constatação de violações sistêmicas aos direitos fundamentais da pessoa humana no sistema educativo daquele país (VIERA JÚNIOR, 2015).

No Brasil, a primeira oportunidade em que o Supremo Tribunal Federal destacou o tema foi em 27 de agosto de 2015, na decisão em medida cautelar na arguição de descumprimento de preceito fundamental 347 do Distrito Federal (ADPF 347/DF). Naquela oportunidade, o Ministro Marco Aurélio realçou as massivas violações de direitos fundamentais vivenciados pela massa carcerária brasileira, cabendo razão ao Poder Judiciário de impor à Administração Pública o dever de adotar medidas urgentes, 
voltadas a cessação de tais violações, caracterizando o sistema penitenciário nacional como um verdadeiro "estado de coisas inconstitucional" (BRASIL, 2015a).

O ECl é uma nova modalidade de inconstitucionalidade, desenvolvida através da técnica jurisdicional e de aplicação decisória, destinada a enfrentar quadros sociais sistemáticos de violações de direitos humanos, resultando da omissão orgânica dos poderes políticos, exigindo-se, para tanto, a atuação direta das Cortes Constitucionais quanto ao destacamento deste panorama e a fiscalização das ações necessárias à sua erradicação, num verdadeiro ativismo judicial, fazendo prevalecer a exegese do conteúdo objeto da norma constitucional $^{1} \quad$ (BRASIL, 2015a; BERNARDI; MEDA, 2016; CAMPOS, 2015; MAGALHÃES, 2019; MACHADO, 2020).

São autênticos cenários de graves violações, atingindo toda a coletividade, resultantes da falta de efetividade das políticas públicas voltadas a proteção e desenvolvimento dos direitos humanos fundamentais, desencadeadas e sustentadas pela atuação Estatal (GUIMARÃES, 2017).

Neste sentido, Alves (2019, p. 217) leciona que "O instituto, uma vez declarado, significa enunciar que determinada situação se acha em uma conjuntura insuportável decorrente de violações aos direitos fundamentais por atos comissivos e omissivos, muitas vezes realizados pelo poder público".

Sob um ponto de vista finalista, o $\mathrm{ECl}$ destina-se à construção de soluções estruturais voltadas a solucionar um cenário acentuado de profanações de direitos fundamentais contra comunidades consideradas vulneráveis (BERNARDI; MEDA, 2016; CUNHA, 2015). Em linhas dogmáticas, a mencionada construção torna-se necessária em razão de desrespeitos sistemáticos do Estado face a concretização jurídico-fundamental presente na Constituição Federal (MAGALHÃES, 2019).

Assim, é exigido das Cortes Constitucionais demonstrações reais de combate às violações sistemáticas, assim como exige-se $o$ controle das ações de execução orientadas na direção protecionista dos direitos fundamentais e alicerçados pela dignidade da pessoa humana,

\footnotetext{
${ }^{1} \mathrm{O}$ conteúdo objetivo da norma constitucional refere-se à vontade da lei, livre de qualquer relação com o subjetivismo do interpreteaplicador (BERNARDI e MEDA, 2016)
}

através de aspectos difusos e igualitários para os seres humanos (CAMPOS, 2015).

As decisões adotadas sob a temática ostentam autêntica natureza estrutural, significando dizer que não sustentam apenas os demandantes processualmente determinados, mas todos aqueles cidadãos que direta ou indiretamente são atingidos pelas massivas violações aos seus direitos fundamentais, mesmo que alheios aos polos processuais (HERNANDÉZ, 2003). Neste passo, tais decisões representam verdadeiras determinações exaradas pelo juiz constitucional para a edição de normas e o desenvolvimento de políticas públicas destinadas a superação das violações de direitos fundamentais em massa (CAMPOS, 2015).

Ao articular sobre esta construção de soluções estruturais, Machado (2020) destacou a força comunicativa que o $\mathrm{ECl}$ impõe entre os sujeitos envolvidos; e Magalhães (2019) destacou a função pedagógica para os demais poderes, direcionando a atuação dos entes públicos para a mesma finalidade, representada pelo resgate integral de validação dos direitos fundamentais. Ocorre uma verdadeira aproximação entre os organismos públicos, viabilizando a edificação de soluções legais e necessárias às massivas violações de direitos fundamentais.

Ao se admitir o $\mathrm{ECl}$ instala-se a certeza de que direitos fundamentais de determinados grupos de pessoas fragilizadas estão sendo violados diante da inércia do Poder Público (CUNHA JÚNIOR, 2020). Neste diapasão, importante ressaltar o caráter pluralístico dos entes públicos responsabilizados direta ou indiretamente pela declaração do $\mathrm{ECI}$, significando dizer que o cenário de violações massivas aos direitos fundamentais não é resultado da ação ou omissão isolada de um único ente público, mas de toda a teia política que envolve a atuação orgânica e sistemática dos diversos poderes da república - Legislativo, Executivo e Judiciário (DANTAS, 2016; ALVES, 2019; MACHADO, 2020).

Neste passo, a objetividade extraída através da declaração do $\mathrm{ECl}$ corresponde ao destacamento dos direitos fundamentais como o único norte aceitável de valores e princípios a serem perseguidos e alcançados pela atuação dos entes públicos de poder, irradiando-se por todo o ordenamento jurídico brasileiro (GUIMARÃES, 2017).

Entre os fatores valorizados pela Corte Constitucional Colombiana para o 
reconhecimento do estado de coisas inconstitucional, evidenciam-se (CORTE CONSTITUCIONAL COLOMBIANA, 2004):

(i) la vulneración masiva y generalizada de varios derechos constitucionales que afecta a un número significativo de personas; (ii) la prolongada omisión de las autoridades en el cumplimiento de sus obligaciones para garantizar los derechos; (ii) la adopción de prácticas

inconstitucionales, como la incorporación de la acción de tutela como parte del procedimiento para garantizar el derecho conculcado; (iii) la no expedición de medidas legislativas,

administrativas $\quad 0$

presupuestales necesarias para evitar la vulneración de los derechos. (iv) la existencia de un problema social cuya solución compromete la intervención de varias entidades, requiere la adopción de un conjunto complejo y coordinado de acciones y exige un nivel de recursos que demanda un esfuerzo presupuestal adicional importante; ( $v$ ) si todas las personas afectadas por el mismo problema acudieran a la acción de tutela para obtener la protección de sus derechos, se produciría una mayor congestión judicial."

No Brasil, seguindo no mesmo norte, Alves (2019) expõe que o $\mathrm{ECl}$ é composto pela soma de três fatores distintos: (i) robusta afronta à direitos fundamentais, ocorrida de forma sistemática e contra pessoas indeterminadas; (ii) ausência de medidas de natureza legislativa, administrativa e judiciária voltadas ao combate do cenário; e (iii) carência de políticas públicas adotadas pelos órgãos imediatamente obrigados.

Uma vez fixados os elementos indicativos deste estado de coisas, cumpre entender qual o papel que a Corte Constitucional responsável deverá desenvolver para abolir tais violações. Neste sentido, o Ministro Marco Aurélio apontou que caberá ao Tribunal exercer uma típica função racionalizadora, destinada a concretizar a operacionalização das normas fundamentais, formadoras do arcabouço jurídico-legal do país (STF, 2015a). Neste sentido, Alves (2019, p. 221) descreve que neste cenário a Corte Constitucional convida "os responsáveis a executarem suas obrigações estabelecidas na constituição". Seguindo entre as interações, Bernardi e Meda (2016, p. 25) ensinam que a decisão que reconhece o $\mathrm{ECl}$ representava verdadeira oportunidade "(...) dialógicas entre as funções, uma vez que essa interação possibilita perspectivas de melhora na realidade de vida das pessoas (...)."

Seguindo por esta linha ativista, Bernardi e Meda $(2016$, p. 13) professam que "O vácuo Legislativo garantidor da falta de eficácia dos direitos fundamentais, aliado à constante omissão do Poder Executivo, transferiu ao Poder Judiciário o condão de fazer valer os ditames constitucionais fundamentais, em especial aqueles que preveem Direitos de cunho social".

A garantia de reconhecimento e aplicação das normas jurídicas frente as injustiças sociais representam verdadeira instrumentalização da dignidade da pessoa humana, assegurando aos cidadãos o acesso a tudo aquilo que compõe a sua essência e a sua trajetória evolutiva (SARLET, 2015).

Nesta senda, ainda se reconhece a possibilidade do Poder Judiciário, através de sua Corte Constitucional, enveredar-se pelos caminhos das políticas públicas, sem que se possa falar em afronta ao princípio democrático e da separação de poderes (BRASIL, 2015b).

$\mathrm{E}$ suma, o reconhecimento do $\mathrm{ECl}$ viabiliza a atuação fiscalizatória do Poder Judiciário, obrigando ${ }^{2}$ os agentes responsáveis

\footnotetext{
2 - Quanto a função fiscalizatória que o Poder Judiciário exerce no desenvolvimento de políticas públicas diante de um cenário de $\mathrm{ECI}$, importante destacar uma nova técnica de controle de constitucionalidade denominada "compromisso significativo" desenvolvida pela Corte Constitucional da África do Sul. Segundo Campos Júnior (2015, p. 30), essa técnica caracteriza-se pela "construção de uma solução pactuada, participativa, sob a fiscalização do Poder Judiciário". Isto significa dizer que não há uma decisão imposta pelo Poder Judiciário ao Poder Executivo, quanto ao atendimento de políticas públicas voltadas a proteção e desenvolvimento dos direitos fundamentais, mas há uma cooperação entre os interessados e o Poder Executivo quanto ao desenvolvimento das políticas públicas de proteção e desenvolvimento dos direitos fundamentais, sob a fiscalização direta do Poder Judiciário.
} 
pelas políticas públicas adotarem medidas efetivas e indispensáveis à cessação das violações aos preceitos fundamentais, construindo uma proteção alicerçada sobre preceitos constitucionais, a fim de comtemplar medidas normativas, administrativas e orçamentárias de combate direto à tais desrespeitos (STRECK, 2015; MAGALHÃES, 2019).

No próximo tópico, serão investigados os fatores formadores da declaração jurisdicional do estado de coisas inconstitucional em matéria ambiental no Brasil, partindo dos ensinamentos expressados pelo Ministro Luís Roberto Barroso na ADPF 708/DF.

\section{0 ESTADO DE COISAS INCONSTITUCIONAL AMBIENTAL.}

O meio ambiente sadio e ecologicamente equilibrado consiste num direito subjetivo do ser humano, esculpido na Constituição Federal Brasileira como verdadeiro direito fundamental, vinculando todos os poderes estatais à sua defesa e proteção (GOMES, 2007).

Esta máxima vem modelada no artigo 225 da Constituição Federal, impondo aos Poderes Públicos e à coletividade o dever de defender e preservar o meio ambiente ecologicamente equilibrado, bem de uso comum, para as presentes e futuras gerações (BORGES; ZIESEMER, 2018).

Para tanto, impõe-se ao Poder Público o dever de desenvolver políticas públicas, criando estruturas e organizando ações voltadas a composição de um desenvolvimento sustentável, objetivando preservar e expandir os limites naturais do meio ambiente ecologicamente equilibrado, como verdadeiro direito fundamental do ser humano.

Essa é a conclusão que se pode extrair do artigo 225, §1‥, da Constituição Federal. Vejamos:

$\S$ 10 Para assegurar a efetividade desse direito, incumbe ao Poder Público: I - preservar e restaurar os processos ecológicos essenciais e prover o manejo ecológico das espécies e ecossistemas; II - preservar a diversidade e a integridade do patrimônio genético do País e fiscalizar as entidades dedicadas à pesquisa e manipulação de material genético; III definir, em todas as unidades da Federação, espaços territoriais e seus componentes a serem especialmente protegidos, sendo a alteração e a supressão permitidas somente através de lei, vedada qualquer utilização que comprometa a integridade dos atributos que justifiquem sua proteção; IV - exigir, na forma da lei, para instalação de obra ou atividade potencialmente causadora de significativa degradação do meio ambiente, estudo prévio de impacto ambiental, a que se dará publicidade; $\mathrm{V}$ - controlar a produção, a comercialização e o emprego de técnicas, métodos e substâncias que comportem risco para a vida, a qualidade de vida e o meio ambiente; VI promover a educação ambiental em todos os níveis de ensino e a conscientização pública para a preservação do meio ambiente; VII proteger a fauna e a flora, vedadas, na forma da lei, as práticas que coloquem em risco sua função ecológica, provoquem a extinção de espécies ou submetam os animais a crueldade. (BRASIL, 1988, não paginado)

Em meados de 2020, aportou no Supremo Tribunal Federal a Ação Direta de Inconstitucionalidade por Omissão número 60 do Distrito Federal - ADO 60/DF - proposta pelos seguintes partidos: Partido Socialista Brasileiro (PSB); Partido Socialismo e Liberdade (PSOL); Partido dos Trabalhadores (PT); e Rede Sustentabilidade. No polo passivo da ação vem a União.

A alegação dos autores indicava a omissão do Governo Executivo Federal em face da gestão do Fundo Clima e de outras matérias de interesse ambiental correlacionados. 0 
Relator responsável para o caso é o Ministro Luís Roberto Barroso, que enfrentando as razões da ADO 60/DF transformou-a em Arguição de Descumprimento de Preceito Fundamental, recebendo o número 708/DF - ADPF 708/DF. Mas antes de materializar esta transformação, o Ministro reconheceu que o Brasil hodiernamente enfrenta um verdadeiro "estado de coisas inconstitucional em matéria ambiental". $\mathrm{Na}$ sequência, o presente trabalho ocupar-se-á com a evidenciação dos alicerces que sustentaram este reconhecimento.

Entre os fundamentos utilizados pelos partidos políticos para a propositura da ADO 60/DF, o Ministro Luís Roberto Barroso (BRASIL, 2020) destacou como atos comissivos:

(i) a redução dos orçamentos e dotações relacionadas ao controle do desmatamento e ao fomento de formas sustentáveis de produção; (ii) o licenciamento de obras de infraestrutura, sem adequada avaliação de impacto; (iii) a desestruturação dos órgãos ambientais federais; (iv) 0 esvaziamento das atribuições do Ministério do Meio Ambiente; (v) a nomeação para cargos importantes de pessoas sem afinidade com a área ambiental; (vi) orientação pública para cessação da demarcação de Terras Indígenas; além de (vii) cortes orçamentários na política ambiental ainda maiores do que os que vinham ocorrendo no passado.

E destacou como atos omissivos:

(i) a falta de reuniões do Comitê Gestor do Fundo, mantido inoperante durante todo o ano de 2019; (ii) a não aprovação do Plano Anual de Aplicação de Recursos, quer para 2019, quer para 2020; (iii) a manutenção de "vultosos recursos 'em caixa' com a rubrica específica de financiar ações voltadas à mitigação de emergências climáticas". No que respeita ao último ponto, os requerentes esclarecem que havia autorização orçamentária para aplicação de R\$ 8.050.000,00 não reembolsáveis para tal fim, tendo sido empenhados apenas R\$ 718.074,00; bem como de mais R\$ 543 milhões reembolsáveis, dos quais foram empenhados apenas R\$ 348 milhões, cujo direcionamento ao BNDES, todavia, não se concretizou. Ainda segundo os requerentes, 0 demonstrativo de movimentação financeira do Fundo Clima do ano de 2019 apontaria um saldo disponível de R\$ 250.074.000,00.

Em linhas cautelares, os requerentes postulavam do STF (BRASIL, 2020) a determinação para que a União "(i) suspenda o comportamento lesivo consistente em não tomar as medidas administrativas necessárias para disponibilizar os recursos relativos ao Fundo Clima; (ii) apresente o Plano Anual de Aplicação de Recursos do Fundo para o ano de 2020 e não se omita de elaborar os demais planos anuais cabíveis; (iii) se abstenha de contingenciar recursos do Fundo."

No mérito, os requerentes postulavam do STF (BRASIL, 2020) a determinação para que a União promovesse “(...) o reconhecimento da inconstitucionalidade da conduta da União na condução do Fundo Clima, bem como na adoção das medidas de proteção ambiental pertinentes à mitigação de mudanças climáticas. Pedem, ainda, a confirmação das cautelares".

Diante das delimitações referidas, o Ministro Luís Roberto Barroso (BRASIL, 2020, p. $5 / 6)$ iniciou sua fundamentação destacando aspectos de que (BRASIL, 2020):

(i) ações e omissões persistentes, comprometedoras da tutela do meio ambiente $\mathrm{e}$ da operação do Fundo 
Clima; (ii) imputáveis a autoridades diversas; e (iii) ensejadoras de violações massivas a direitos fundamentais, tudo a sugerir a existência de um estado de coisas inconstitucional em matéria ambiental.

Assim, os fundamentos considerados para o reconhecido do $\mathrm{ECl}$ em matéria ambiental surgiu de condutas ativas e passivas adotadas por algumas autoridades públicas ligadas à União, comprometendo a proteção do meio ambiente a partir da defeituosa operação do Fundo Nacional de Mudanças Climáticas ${ }^{3}$ - Fundo Clima ${ }^{4}$. Importante destacar que o Fundo Clima foi concebido como um instrumento público destinado a fomentar a redução da emissão de gases que causam o efeito estufa.

Seguindo por este norte, o Ministro Luís Roberto Barroso vinculou o fracasso da União em conduzir os investimentos do Fundo Clima ao aumento da devastação florestal em todo o Brasil, destacando em sua decisão que até 2004 o Brasil pouco se preocupava com a repressão de ações voltadas ao desmatamento, ocasionando diversas perdas para o País perante as políticas internacionais. De 2004 até 2013, o Brasil experimentou um período de combate e controle das ações de devastamento, mas a partir deste ano os índices voltaram a aumentar, fazendo com que novamente o país sofresse com reprovações internacionais (BRASIL, 2020).

Como indicativos desta afirmação, de acordo com o Imazon, em outubro de 2020 foram detectados 890 quilômetros quadrados de desmatamento ilegal na Amazônia para o ano. Em porcentagens, tais números representam um aumento de $49 \%$ em relação a outubro de 2019 , quando $\mathrm{o}$ desmatamento alcançou 598

\footnotetext{
3 - O Fundo Nacional de Mudanças Climáticas foi oficialmente criado pela lei 12.114, de 09 de dezembro de 2009. Segundo Cardial (2020), os recursos financeiros do Fundo tiveram sua primeira previsão orçamentária no ano de 2011, perdurando até o ano de 2018, quando o Governo Federal cessou com seu planejamento.

4 - O "Fundo Clima" corresponde a um instrumento operado pela Política Nacional sobre Mudança do Clima, com natureza econômica e vinculado ao Ministério do Meio Ambiente. Sua finalidade é garantir recursos financeiros necessários ao apoio de projetos e estudos voltados ao combate das mudanças climáticas (Instituto de Pesquisa Econômica Aplicada - Ipea; Cooperação Alemã para o Desenvolvimento, por meio da Deutsche Gesellschaft für Internationale Zusammenarbeit (GIZ) $\mathrm{GmbH}$; Ministério do Meio Ambiente - MMA; e Comissão Econômica para a América Latina e o Caribe - CEPAL, 2016)
}

quilômetros quadrados no mesmo período (FONSECA, 2020).

Conforme destacou o Ministro, ambientalistas e estudiosos da área ambiental apontam que o crescimento da devastação florestal nos últimos anos se deve principalmente às políticas públicas adotadas pelo Governo Federal. Em matéria intitulada "Medidas do Ministério do Meio Ambiente geram críticas internacionais", publicada pelo "Jornal da USP", em 07 de junho de 2019, restou destacada a preocupação de diversos países com a política ambiental defendida pelo Ministro brasileiro do Meio Ambiente Ricardo Salles.

Naquela oportunidade, o Professor Pedro Luiz Cortês, do Programa de Pós Graduação em Ciências Ambientais do Instituto de Energia e Ambiente da USP, ressaltou a preocupação com o crescimento do desmatamento na Amazônia naquele ano, atingindo números recordes de aumento de 34\% (ALEGRE, 2019).

Em entrevista ao programa "Roda Viva", no dia 07 de dezembro de 2020, a diretora executiva internacional do "Greenpeace", Jennifer Morgan, destacou que, ao analisar os recentes números de queimadas e derrubada de árvores no território brasileiro, restou evidenciado que isso ocorre em razão das medidas governamentais de desmantelamento de agências ambientais, resultando no enfraquecimento da estrutura institucional e legal (MORGAN, 2020).

Seguindo pelos fundamentos, em recente trabalho publicado por Barroso e Mello (2020) foram destacados diversos fatores políticos, sociais e econômicos responsáveis pelo aumento vertiginoso da devastação florestal: (i) a extinção da Secretaria de Mudanças do Clima e Florestas do Ministério do Meio Ambiente através do Decreto no 9.672, de 2 janeiro de 2019; (ii) a eliminação da Subsecretaria Geral de Meio Ambiente, Energia e Ciência e Tecnologia do Ministério das Relações Exteriores através do Decreto no 9.683, de 9 janeiro de 2019; (iii) o desligamento de diversos agentes do Instituto Brasileiro do Meio Ambiente; (iv) a compactação dos números de membros do Conselho Nacional do Meio Ambiente - CONAMA, reduzindo a participação de ONGs, Estados e representantes da sociedade civil; (v) a mudança do Serviço Florestal Brasileiro para o Ministério da Agricultura, Pecuária e Abastecimento, através do decreto no 9.667, de 2 de janeiro de 2019, representando interesses conflitantes; (vi) a 
migração da competência para demarcação de terras indígenas da Fundação do Índio (FUNAI) para o Ministério da Agricultura; (vii) as diversas manifestações de hostilidade do Governo Federal em relação às organizações não governamentais destinadas a proteção do meio ambiente; e (viii) o extermínio do Comitê Orientador do Fundo Amazônia, através do decreto no 9.759, de 11 de abril de 2019, que detinha atribuição para apontar parâmetros e fiscalizar a efetividade dos recursos financeiros do Fundo Amazônico.

Corroborando os apontamentos alhures, Borges e Ziesemer (2018, p. 161) destacam que "Outro fator que contribui para a continuidade do estado de coisas inconstitucional ambiental é a problemática orçamentária. Sem o devido aparelhamento dos órgãos de fiscalização, em quantidade e qualidade, pouco ou nada adiantam a correção dos rumos legislativos."

Em reportagem publicada em 02 de setembro de 2020, pela Organização Não Governamental "O Eco", restou evidenciado que o Governo Federal enviou ao Congresso Nacional - Projeto de Lei Orçamentária para 2021, prevendo um corte de $\mathrm{R} \$ 184$ milhões para o Ministério do Meio Ambiente (BRAGANÇA, 2020). Tais reduções resultarão no arrefecimento das ações de fiscalização e combate ao desmatamento e queimadas nos mais diversos sistemas florestais brasileiros, além de enfraquecer a representatividade de organizações voltadas a proteção ambiental, como o IBAMA e o ICMBio (UOL, 2020).

Em suma, fatores de ordem política, social e orçamentário ${ }^{5}$ serviram de sustentáculo para a decisão do Ministro Luís Roberto Barroso quanto ao reconhecimento do $\mathrm{ECl}$ ambiental brasileiro na ADO 60/DF. Ofertando suas conclusões, ele expõe (BRASIL, 2020, p. 9):

Tudo sugere, portanto, uma trajetória contínua, progressiva e preocupante de esvaziamento das políticas públicas brasileiras em matéria ambiental, agravada exponencialmente no

\footnotetext{
Os fatores sociais, políticos e econômicos também foram destacados por Breno Baía Magalhães, em seu artigo denominado "O Estado de Coisas Inconstitucional na ADPF 347 e a Sedução do Direito" como preponderantes para o reconhecimento do $\mathrm{ECl}$ na análise da ADPF 347, pelo STF, quando enfrentou o problema dos presídios brasileiros. Nota-se, com isso, que tais fatores são recorrentes nas discussões que sustentam como "pano de fundo" a declaração do $\mathrm{ECl}$, uma vez que tais naturezas também foram destacadas na declaração do $\mathrm{ECl}$ ambiental.
}

último ano e meio. De fato, tal estado de coisas envolve não apenas o direito de todos a um meio ambiente saudável em si (art. 225, CF), mas produz reflexos sobre um amplo conjunto de outros direitos fundamentais protegidos pela Constituição de 1988, como o direito à vida (art. 5ㅇ, CF), à saúde (art. 6ㅇ, CF), à segurança alimentar e à água potável (art. 60, $\mathrm{CF}$ ), à moradia (no sentido de habitat), ao trabalho (art. 70, CF), podendo impactar, ainda, o direito à identidade cultural, o modo de vida e a subsistência de povos indígenas, quilombolas e demais comunidades tradicionais (art. 23, III, art. 215, caput e $\S 10$ e art. $216 \mathrm{c} / \mathrm{c}$ art. 231, CF e art. 68, ADCT).

A subsistência deste quadro de violações massivas e persistentes contra o meio ambiente ecologicamente equilibrado afronta a dignidade da pessoa humana, retirando que Alves (2019) denominou a efetividade das normas consolidadoras dos direitos fundamentais, demandando assim uma atuação afirmativa do Poder Judiciário em impor ao Poder Executivo obrigações voltadas à prevenção e recuperação dos processos ecológicos essenciais à vida humana, resgatando a efetividade de tais normas (MACHADO, 2020).

\section{CONSIDERAÇÕES FINAIS}

O meio ambiente, ecologicamente equilibrado, conforme disposto no artigo 225 da Constituição Federal do Brasil tem natureza de direito fundamental, sendo encarado como condição essencial ao desenvolvimento digno do cidadão.

O ECl trata-se de verdadeira técnica de natureza jurídico-constitucional, responsável por evidenciar falhas político-administrativas enraizadas no âmago do Poder Público, impulsionando violações massiva de direitos fundamentais da pessoa humana. 
Voltando os olhos à questão ambiental, o Ministro Luís Roberto Barroso, na ADPF 708/DF, reconheceu que há no Brasil um perene e massivo estado de degradação ambiental conjugado a partir da inexpressiva gestão dos recursos encontrados no programa "Fundo Clima", sendo que tal cenário resulta de imperfeições generalizadas presentes em decisões da União sobre a preservação dos recursos naturais, revelando um verdadeiro cenário permanente de desestruturação ambiental, lesionando o direito fundamental do homem à vida através do meio ambiente ecologicamente equilibrado.

A evidenciação dos fundamentos que sustentaram a decisão do Ministro Luís Roberto Barroso sobre o $\mathrm{ECl}$ em matéria ambiental no território brasileiro auxiliará no real entendimento da complexidade ambiental enfrentado pelo Brasil na atualidade, possibilitando a adoção de medidas nas áreas executiva, legislativa e judiciária, voltadas à efetivação de direitos fundamentais ligados ao meio ambiente sadio e ecologicamente equilibrado.

Este cenário de inconstitucionalidade estrutural em material ambiental apresenta três níveis de fatores:

1. Nível Político: representado pela extinção de órgãos públicos voltados a proteção do meio ambiente e desenvolvimento dos recursos florestais; o desligamento de agentes públicos empenhados na proteção do meio ambiente; e a realocação de comitês e outros entes relacionados à proteção ambiental para órgãos que cuidam de interesses essencialmente antagônicos.

2. Nível Social: manifestações públicas de hostilidade do Governo Federal contra organizações não governamentais e pessoas físicas vinculadas a luta de proteção do meio ambiente.

3. Nível Orçamentário: a contenção orçamentária em ações de fiscalização do desmatamento e ao estímulo de formas sustentáveis de produção.

O presente artigo limitou-se a evidenciar à comunidade científica, através de um estudo direcionado, os fundamentos sociais, políticos e orçamentários considerados pelo Ministro Luís Roberto Barroso na ADPF708/DF. Neste passo, futuras pesquisas quanto à evolução das condições estruturantes destes fatores é de interesse da sociedade civil e da comunidade científica, verificando a efetividade da técnica jurisdicional do $\mathrm{ECl}$ em matéria ambiental.

\section{REFERÊNCIAS}

ALEGRE, Laura. Medidas do Ministério do Meio Ambiente geram críticas internacionais. Jornal da USP, São Paulo, 2019. Disponível em: https://jornal.usp.br/atualidades/medidas-doministerio-do-meio-ambiente-geram-criticasinternacionais/. Acesso em: 07 dez. 2020.

ALVES, Andréa Karla da Silva. O Estado de Coisas Inconstitucional e a Tutela dos Direitos Humanos Fundamentais. Revista Digital Constituição e Garantia de Direitos, Natal, v. 11, n. 2. P. 210228, 2019. Disponível em: https://periodicos.ufrn.br/constituicaoegarantiad edireitos/article/view/16136/11380. Acesso em: 05 jan. 2021.

BARROSO, Luís Roberto; MELLO, Patrícia Perrone Campos. Como Salvar a Amazônia: Por que a floresta de pé vale mais que derrubada. Revista de Direito da Cidade. Rio de Janeiro, v. 12, n. 2, p. 331-376, 2020. Disponível em: https://www.epublicacoes.uerj.br/index.php/rdc/article/view/5 0980/34015. Acesso em: $07 \mathrm{dez}$. 2020. DOI https://doi.org/10.12957/rdc.2020.50980.

BERNARDI, Renato; MEDA, Ana Paula. Da tripartição de poderes ao estado de coisas inconstitucional e o "compromisso significativo": a contemporânea atuação do Poder Judiciário na solução de conflitos que envolvem direitos sociais fundamentais. Em tempo - Revista da área de direito da UNIVEM, Marília, v. 15, p. 11-34, 2016. DOI https://doi.org/10.26729/et.v15i0.1654.

BORGES, Luiz Fernando Rossetti; ZIESEMER, Henrique da Rosa. O estado de coisas inconstitucional e as áreas urbanas consolidadas: entre a descaracterização do meio ambiente e a restauração. RFD - Revista da Faculdade de

Direito da UERJ, Rio de Janeiro, v. 33, p. 151-169, jun. 2018. Disponível em: https://www.epublicacoes.uerj.br/index.php/rfduerj/article/vie w/26552/25926. Acesso em: 08 dez. 2020. DOI https://doi.org/10.12957/rfd.2018.26552 
BRAGANÇA, Daniele. Governo reduz em $\mathrm{R} \$ 184,4$ mi o orçamento de 2021 do Ministério do Meio Ambiente. O Eco. 2020. Disponível em: https://www.oeco.org.br/blogs/saladaverde/governo-reduz-em-r-1844-mi-oorcamento-de-2021-do-ministerio-do-meioambiente/ . Acesso em: 08 dez. 2020.

BRASIL. Supremo Tribunal Federal. Medida cautelar na arguição de descumprimento de preceito fundamental 347 Distrito Federal. Requerente: Partido Socialismo e Liberdade PSOL. Relator: Min. Marco Aurélio. Brasília (DF), 09 de Setembro de 2015a. Disponível em: http://redir.stf.jus.br/paginadorpub/paginador.js $p$ ?docTP=TP\&docID=10300665. Acesso em: 12 Out. 2020.

BRASIL. Supremo Tribunal Federal. Recurso Extraordinário 592.581 Rio Grande do Sul. Reclamante: Ministério Público do Estado do Rio Grande do Sul. Reclamado: Estado do Rio Grande do Sul. Relator: Min. Ricardo Lewandowski. Brasília (DF), 13 de Agosto de 2015b. Disponível em:

http://redir.stf.jus.br/paginadorpub/paginador.js $p$ ?docTP=TP\&docID=10166964 . Acessado em: 04 Dez. 2020.

BRASIL. Supremo Tribunal Federal. Arguição de Descumprimento de Preceito Fundamental 708 - Distrito Federal. Requerente: Partido Socialista Brasileiro - PSB, Partido Socialismo e Liberdade P-SOL, Partido dos Trabalhadores - PT; e Rede Sustentabilidade. Relator: Min. Luís Roberto Barroso. Brasília (DF), 28 de Junho de 2020. Disponível em: http://www.stf.jus.br/arquivo/cms/noticiaNoticia Stf/anexo/ADO60Decisa771oaudie770nciapu769 blica.pdf. Acessado em: 26 Nov. 2020.

CAMPOS. Carlos Alexandre de Azevedo. Da inconstitucionalidade por omissão ao "Estado de coisas inconstitucional". 2015. 248 f. Tese (Doutorado em Direito) - Universidade do Estado do Rio de Janeiro. Rio de Janeiro, 2015.

CARDIAL. Julianna Colonna Valevski. Instrumentos de ação pública: uma análise da política nacional sobre mudanças climáticas e o Fundo Clima. 2020. 162 f. Dissertação (Mestrado em Ciências) - Universidade de São Paulo (USP). São Paulo, 2020.
CORTE CONSTITUCIONAL DA COLÔMBIA. Sentença T-025/04. 2004. Disponível em: https://www.corteconstitucional.gov.co/relatoria /2004/t-025-04.htm. Acesso em: 03 dez. 2020.

CUNHA JÚNIOR, Dirley. Estado de Coisas Inconstitucional. Brasil Jurídico. Salvador, 2015. Disponível em: https://brasiljuridico.com.br/artigos/estado-decoisasinconstitucional\#: :text=Mas\%20onde\%20surgiu \%20isso\%3F,e\%20sistem\%C3\%A1ticas\%20de\%20 direitos\%20fundamentais. Acesso em: 18 nov. 2020.

DANTAS, Eduardo Sousa. Ações estruturais, direitos fundamentais e o estado de coisas inconstitucional. Revista Constituição e Garantias de Direitos, Rio Grande do Norte, v. 9, n. 2, 2016.

FONSECA, A. Boletim do Desmatamento da Amazônia Legal (outubro de 2020). Amazônia: Imazon, $2020 . \quad$ Disponível em: https://imazon.org.br/publicacoes/boletim-dodesmatamento-da-amazonia-legal-outubro-2020sad/ . Acesso em: 07 Dez. 2020.

GOMES, Daniela Vasconcellos. A importância do exercício da cidadania na efetivação do direito fundamental ao meio ambiente ecologicamente equilibrado. 2007. 120 f. Dissertação (Mestrado em Direito) - Universidade de Caxias do Sul, Caxias do Sul. 2007.

GUIMARÃES, Mariana Rezende. O estado de coisas inconstitucional: perspectiva de atuação do Supremo Tribunal Federal a partir da experiência da Corte Constitucional colombiana. Boletim Científico ESMPU, Brasília, a. 16, n. 49, p. $79-111$ - jan./jun. 2017.

HERNANDÉZ, Clara Inés Vargas. La garantia de la dimensión objetiva de los derechos fundamentales y labor del juez constitucional colombiano em sede de acción de tutela: el llamado "estado de cosas inconstitucional". Revista del Centro de Estudios Constitucionales, Chile, v. 1, n. 1, 2003.

MACHADO, Maira Rocha. Quando o estado de coisas é inconstitucional: sobre o lugar do Poder Judiciário no problema carcerário. Revista de Investigações Constitucionais, Curitiba, v. 7, n. 2, 
p. 631-664, maio/ago. 2020. DOI https://doi.org/10.5380/rinc.v7i2.60692.

MAGALHÃES, Breno Baía. O estado de coisas inconstitucional na ADPF 347 e a sedução do direito: o impacto da medida cautelar e a resposta dos poderes políticos. Revista Direito GV, São Paulo, v. 15, n. 2, 2019. Disponível em: http://bibliotecadigital.fgv.br/ojs/index.php/revdi reitogv/article/view/80272/76708. Acesso em: 08 jan. 2021. DOI https://doi.org/10.1590/2317$\underline{6172201916 .}$

MAZIEIRO, Guilherme; TEMÓTEO, Antonio. Governo Bolsonaro prevê corte de $\mathrm{R} \$ 184,4 \mathrm{mi}$ do meio ambiente para 2021. UOL, Brasília, 31 ago, $2020 . \quad$ Disponível em: https://noticias.uol.com.br/meioambiente/ultimasnoticias/redacao/2020/08/31/governobolsonaro-corta-r-1844-mi-do-meio-ambientepara-2021.htm . Acesso em: 08 Dez. 2020.

MICHAELS, Lothar; MARTIN, Morlok. Série IDP Direitos fundamentais. São Paulo: Saraiva, 2016. Disponível em: https://integrada.minhabiblioteca.com.br/\#/book s/9788547212421/. Acesso em: 17 dez. 2020.

MILARÉ, Edis. Direito do Ambiente: doutrina, prática, jurisprudência, glossário. São Paulo. Editora Revista dos Tribunais. 2000.

MORAES. Alexandre de. Direito Constitucional. 29. ed. São Paulo: Atlas, 2013.

ONU. Declaração de Estocolmo sobre ambiente humano, jun. de 1972. Disponível em: http://www.direitoshumanos.usp.br/index.php/ Meio-Ambiente/declaracao-de-estocolmo-sobreo-ambientehumano.html\#: :text=0\%20homem\%20tem\%20 o\%20direito,as\%20gera\%C3\%A7\%C3\%B5es\%20pr esentes\%20e\%20futuras. Acesso em: $02 \mathrm{dez}$. 2020.

MORGAN, Jennifer. Programa Roda Viva. 07 dez. 2020]. TV Cultura. São Paulo, 2020. Disponível em: https://cultura.uol.com.br/noticias/14592_rodaviva-esta-claro-que-o-governo-bolsonaro-que-eresponsavel-diz-diretora-do-greenpeace-sobrequeimadas.html. Acesso em: 08 dez. 2020.
ROTHENBURG, Walter Claudius. Série Carreiras Federais: direitos fundamentais. São Paulo: Grupo GEN, 2014. Disponível em: https://integrada.minhabiblioteca.com.br/\#/book s/978-85-309-5544-1/. Acesso em: 17 dez. 2020.

SARLET, Ingo Wolfgang. Dignidade (da Pessoa) Humana e Direitos Fundamentais na Constituição Federal de 1988. 10. ed. Porto Alegre: Livraria do Advogado Editora. 2015.

SARLET, Ingo Wolfgang. MACHADO, Paulo Affonso Leme. FENSTERSEIFER, Tiago. Constituição e legislação ambiental comentada, 1. ed. São Paulo: Saraiva, 2015. Disponível em: https://integrada.minhabiblioteca.com.br/\#/book s/9788502626492/. Acesso em: 12 Dez. 2020.

SILVA, Solange Teles da. Direito Fundamental ao Meio Ambiente Ecologicamente Equilibrado Avanços e Desafios. Cadernos do Programa de Pós-Graduação em Direito-PPGDir./UFRGS, n. 6, p. 169/188, 2006.

STRECK, Lenio Luiz. Estado de Coisas Inconstitucional é uma nova forma de ativismo. Conjur, São Paulo, out., 2015 Disponível em: https://esmec.tjce.jus.br/wp-

content/uploads/2016/02/Estado-de-CoisasInconstitucional.pdf . Acesso em 18 nov. 2020.

VIEIRA JUNIOR, Ronaldo Jorge Araújo. Separação de Poderes, Estado de Coisas Inconstitucional e Compromisso Significativo: novas balizas à atuação do Supremo Tribunal Federal. Brasília: Senado Federal, 2015. Disponível em: https://www2.senado.leg.br/bdsf/handle/id/516 692 . Acesso em: 1 dez. 2015. 